\title{
Determinantes Psicobiológicos do Comportamento Alimentar: uma ÊNFASE EM Fatores Ambientais Que Contribuem PARA A OBESIDADE $^{1}$
}

\section{Teresa Cristina Bolzan Quaioti ${ }^{2}$ e Sebastião de Sousa Almeida ${ }^{3}$ \\ Universidade do Sagrado Coração - USC Universidade de São Paulo - USP}

$O$ comportamento alimentar é multideterminado e somente uma análise psicobiológica é capaz de abordar as interações entre os fatores fisiológicos, psicológicos, genéticos e condições ambientais de um indivíduo. Assim, a capacidade para controlar a ingestão requer mecanismos especializados para harmonizar informações fisiológicas do meio interno com informações nutricionais do ambiente externo. Dentre os fatores externos merece destaque a questão ligada à propaganda de alimentos e a influência cada vez maior da mídia na determinação da dieta dos indivíduos de países desenvolvidos ou em desenvolvimento. Assim, o presente trabalho tem por objetivo analisar as influencias dos fatores ambientais na determinação do comportamento alimentar humano, com especial ênfase naqueles fatores que podem predispor à obesidade.

Descritores: Comportamento alimentar. Ambiente. Obesidade.

1 Artigo originado da tese de doutoramento da primeira autora defendida em 2002 no Programa de Psicobiologia da Faculdade de Filosofia, Ciências e Letras de Ribeirão Preto - USP. Apoio financeiro do CNPq.

2 Docente da Universidade do Sagrado Coração - USC (Bauru - SP). Endereço eletrônico: tcbolzan@yahoo.com.br

3 Docente da Faculdade de Filosofia, Ciências e Letras de Ribeirão Preto - USP. Endereço eletrônico: sebasalm@usp.br 


\section{Comportamento Alimentar}

comportamento é entendido como uma função conjunta de fatores filogenéticos, que operam durante o processo de evolução de uma dada espécie, e de fatores ontogenéticos, que operam nas interações de um dado organismo dessa espécie com seu ambiente (Catania, 1999).

Em relação ao comportamento alimentar vários fatores filogenéticos e ontogenéticos foram identificados (Mariani-Costantini, 2000; Milton, 2000). Cada espécie, em geral, e cada indivíduo, em particular, está sujeito a fatores genéticos na escolha de que tipos de alimentos consumir e da quantidade. Ultimamente tem-se demonstrado (De Castro \& Plunkett, 2001) que o papel dos genes é cada vez mais importante na determinação das relações palatabilidade-ingestão. Há evidências de que os genes podem estar na determinação de fatores tão gerais como preferências e responsividade a alimentos, ingestão, nível metabólico basal, atividade física, e gastos energéticos. Certamente em humanos a questão da ontogenia assume primordial importância uma vez que, dentre todos os animais, o bebê humano é o que mostra maior dependência em relação aos seus genitores tendo, portanto, um longo período de socialização. Por outro lado, características essencialmente humanas permitiram o surgimento da cultura (Asp, 1999), fator este que não deve ser negligenciado no comportamento alimentar. Desta forma, poderíamos então falar de determinantes psicobilógicos para nos referirmos a essa multideterminação da conduta alimentar (Netto, 1998). O comportamento alimentar humano refletiria interações entre o estado fisiológico, o estado psicológico e as condições ambientais de um dado indivíduo. Assim, a capacidade para controlar a ingestão requer mecanismos especializados para harmonizar informações fisiológicas do meio interno com informações nutricionais do ambiente externo. As informações do meio interno dizem respeito a neurotransmissores, hormônios, taxa metabólica, estados do sistema gastrointestinal, tecidos de reserva, formação de metabólitos e receptores sensoriais. As informações do meio externo dizem respeito a características dos alimentos (sabor, familiaridade, textura, composição nutricional e variedade) e características do ambiente (temperatura, localidade, trabalho, oferta ou escassez de alimentos, assim como crenças sociais, culturais e religiosas). Os fatores biológicos da determinação do comportamento alimentar tiveram precedência como assunto de investigação científica 
Determinantes Psicobiológicos do Comportamento Alimentar: uma Ênfase...

e, hoje, dispomos de uma vasta literatura a respeito do assunto (De Castro \& Plunkett, 2001). Somente mais tarde surgiu o interesse por outros fatores que podem estar na gênese do comportamento alimentar. Dentre eles merecem destaque os fatores sócio-culturais (renda, regionalismo, tabus alimentares) e fatores psicológicos (aprendizagem, motivação, emoção). Ainda com relação aos fatores sócio-culturais merece destaque a questão ligada à propaganda de alimentos e à influência da mídia na determinação da dieta dos indivíduos (Almeida, Nascimento, \& Quaioti, 2002; Caldeira, 2000; De Assis, 2000).

Talvez a mais remota influência do ambiente no comportamento alimentar seja ainda durante a gestação. Tem-se demonstrado, tanto em animais como em humanos, que o filhote tende a consumir alimentos que foram consumidos pela mãe durante a gestação e lactação (Galef, 1982; Galef \& Handerson, 1972; Sullivan \& Birch, 1994). Mais tarde este comportamento tende a se repetir com o consumo de alimentos que os adultos de seu grupo social consomem. Este comportamento provavelmente tem razões evolutivas uma vez que animais de diferentes espécies ingerem diferentes itens alimentares. Entretanto, desde logo se observam influências ambientais que participam na escolha de alimentos pelos jovens de uma dada espécie. São ilustrativos os dados de experimentos que mostram que ratos jovens escolhem o alimento por observação do comportamento alimentar dos adultos (Galef, 1982). Sabe-se que para uma alimentação adequada o indivíduo necessita de uma variedade de alimentos presentes em seu ambiente e que, muitas vezes, seu comportamento exige uma habituação a alimentos novos. Essa habituação se constitui em um dos processos mais simples de aprendizagem mostrando que, desde muito cedo, a experiência tem um papel fundamental na formação dos padrões de aceitação ou recusa de certos alimentos (Birch, 1999).

Desta forma, relações genes-ambiente determinarão, em grande parte, os itens alimentares normalmente procurados e consumidos, o que caracterizaria o que chamamos hábito alimentar ou comportamento alimentar do organismo. Deve-se ressaltar, entretanto, que o hábito alimentar não é sinônimo de "preferências alimentares", uma vez que o termo "preferência" diz respeito somente ao fato de um dado organismo consumir os alimentos de que mais gosta quando lhe é dada a oportunidade da escolha (Ramos \& Stein, 2000). 
Assim, o presente trabalho tem por objetivo discutir a influência de fatores ambientais na determinação do comportamento alimentar humano, com especial ênfase naqueles fatores que podem predispor à obesidade. Serão discutidos determinantes ambientais do comportamento alimentar que podem predispor à obesidade, adotando como estratégia uma análise por período de desenvolvimento do ser humano - lactantes, pré-escolares, escolares, adolescentes e adultos.

\section{Lactantes: o início de tudo}

É no início da vida que o hábito alimentar começa a ser formado, sendo necessária uma compreensão dos seus fatores determinantes. No comportamento alimentar humano podemos verificar que bebês iniciam a vida consumindo uma dieta láctea e logo suas experiências dietéticas começam a se diferenciar. Neste período a alimentação do lactante depende inteiramente dos adultos que lhe dispensam cuidados. Se a criança é amamentada ao seio a quantidade e qualidade do leite produzido vai depender do estado nutricional e dos hábitos alimentares da mãe. Se a criança é alimentada artificialmente outros fatores ambientais estarão em jogo. Grande parte das informações disponíveis para as mães diz respeito aos períodos de gestação e lactação. Neste período o sistema nacional de saúde e os meios de comunicação desenvolvem uma série de campanhas de informação instruindo as mães a não consumir itens que possam ser prejudiciais ao desenvolvimento do bebê, além de enfatizar itens que contenham os nutrientes necessários a uma boa saúde do feto e do recém-nascido.

Entretanto, a partir dos dois anos de idade as mensagens veiculadas mudam drasticamente (Schwartz \& Puhl, 2003), com as crianças se tornando alvos da publicidade de uma infinidade de itens alimentares não saudáveis. E é neste ambiente de pouca informação e muita propaganda que cada criança vai desenvolver seu próprio padrão de aceitação ou rejeição de alimentos (Birch, 1999).

Desde muito cedo a criança estará exposta a uma infinidade de estímulos ligados aos alimentos, estímulos estes que envolvem vários sistemas sensoriais, como o paladar, olfato e visão, todos cruciais na determinação da escolha (Birch, 1992). Sabe-se que bebês nascem com alguma predisposição para preferir substâncias doces e rapidamente desenvolvem uma preferência por substâncias 
Determinantes Psicobiológicos do Comportamento Alimentar: uma Ênfase...

salgadas (Cowart, 1981). Estas preferências herdadas podem ter servido a um propósito evolutivo uma vez que substâncias doces poderiam predizer o valor energético do alimento. Porém, nos dias de hoje o fato da oferta de substâncias doces e salgadas ser tão prevalente em nossa sociedade torna o valor destas preferências desnecessário e até mesmo perigoso (Schwartz \& Puhl, 2003).

Assim, no início da vida, os lactentes normalmente respondem com expressão facial positiva ao sabor doce e com expressão facial negativa aos sabores azedo e amargo, sendo estas expressões utilizadas pelos adultos para interpretar as preferências alimentares (Koivisto \& Sjödén, 1996). Desta forma, o comportamento alimentar da criança, durante a amamentação e o desmame, é altamente influenciado pela família e, secundariamente, pelas interações psico-sociais e culturais que começam, mais ou menos cedo, de acordo com cada grupo populacional a que a criança pertence (Fonseca, Sichieri, \& Veiga, 1998; Ramos \& Stein, 2000). Mesmo nesta fase precoce do estabelecimento do comportamento alimentar as crianças apresentam preferências e, muitas vezes, é difícil fazer com que variem a alimentação, pois muitas têm receio de experimentar novos alimentos e sabores, fenômeno este denominado de neofobia alimentar (Birch \& Fisher, 1995). Para enfrentar a neofobia os pais podem incentivar o consumo de outros alimentos e, se assim o fizerem, estarão permitindo contato com outros sabores, cheiros e texturas que não conheciam, dando oportunidade do aprendizado sobre outros itens alimentares presentes no ambiente. Neste tipo de aprendizagem estão envolvidos, além dos aspectos ligados à novidade dos alimentos, também outros, ligados ao contexto social onde o alimento foi consumido, à quantidade que deve ser consumida, assim como às conseqüências pós-ingestão (Birch \& Fisher, 1997). Por outro lado, se os pais não incentivarem o comportamento de ingerir alimentos variados estarão restringindo as experiências alimentares e contribuindo para uma dieta monótona e, possivelmente, desbalanceada para um bom desenvolvimento físico e cognitivo.

\section{Pré-escolares: a preferência começa a se estabelecer}

Logo após o desmame a diversidade de itens consumidos pelas crianças aumenta consideravelmente. É uma fase crítica uma vez que a criança vai 
ser influenciada pelo que a família consome. Se o grupo familiar consome uma dieta equilibrada e saudável as chances da criança aprender bons hábitos alimentares são grandes. Caso contrário corre-se o risco da criança iniciar o estabelecimento de hábitos alimentares incorretos com sérios riscos para a saúde no futuro. Em pré-escolares é comum o hábito alimentar caracterizar-se por preferências, pois nessa idade as crianças acabam consumindo, na maioria das vezes, somente os alimentos de que gostam, evitando aqueles de que não gostam (Birch, 1998). Deve-se também salientar que além da neofobia e das preferências inatas por doces, crianças parecem também estar predispostas a preferir alimentos densamente calóricos e com altos índices de gordura (Birch \& Fisher, 1998). Nessa idade ainda é grande a influência do grupo familiar, de modo que o estabelecimento de uma dieta adequada para o crescimento e desenvolvimento satisfatórios é perfeitamente possível se assim os pais o desejarem. Portanto, os pais têm participação fundamental na escolha dos alimentos, pois as crianças não permanecem o dia todo na escola e a maior parte das refeições ainda feita em casa. Sabe-se que não basta o desejo dos pais uma vez que diversos outros fatores podem influenciar na dieta tais como: nível de formação e informação dos pais, trabalho dos pais fora de casa, informação da criança pela mídia e influência de outras crianças. Na medida em que a criança cresce os pais têm menos controle sobre a alimentação, uma vez que estas passam a tomar suas próprias decisões sobre a alimentação e a selecionar os alimentos que desejam ingerir. Cerca de $86 \%$ das crianças afirmam "comer o que querem, quando querem e onde querem". No Brasil esse percentual é de 63\% nos dias de hoje contra 24\% em 1960 (Martins-Filho, 2001).

Nesta idade as crianças preferem alimentos com quantidade elevada de carboidrato, açúcar, gordura e sal em detrimento de vegetais e frutas (KrebsSmith et al., 1996). Um fator importante na escolha dos alimentos gordurosos é a palatabilidade, além de mais calóricos e mais aceitos devido à sensação de maior saciedade (Birch, 1992). Obviamente a indústria de alimentos conhece essa preferência, o que influencia a composição dos alimentos ofertados pelas empresas do setor. Além disso, tais empresas investem muito na propaganda dos produtos, sendo a televisão o principal meio de comunicação utilizado (Almeida et al., 2002). Nas grandes redes de supermercados os alimentos são dispostos ao nível dos olhos das crianças para que possam reconhecer as marcas mais veiculadas e possam alcançar facilmente estes produtos durante as 
Determinantes Psicobiológicos do Comportamento Alimentar: uma Ênfase...

compras. Dados de 1997 mostram que nos EUA a industria de alimentos foi a segunda maior anunciante, sendo a televisão o meio mais popular (Gallo, 1998). A promoção de "snacks" (doces, chicletes, balas, bolos, bolachas e chips) utilizou uma verba sete vezes maior que aquela gasta com a promoção destinada ao consumo de frutas, vegetais, grãos e feijões (Gallo, 1998).

\section{Escolares: com os pés fora de casa, um mundo de cores e sabores.}

Nessa fase, para o desespero de alguns pais e a indiferença de outros, as crianças ganham a rua, a escola, o supermercado e o shopping. Nestes locais haverá oferta e diversidade de alimentos coloridos, saborosos e baratos, que não necessitarão ser apresentados às crianças, uma vez que já entraram em suas casas através da agressiva propaganda das indústrias alimentícias. Sabese que os anúncios na televisão estimulam as crianças a consumir alimentos com elevado grau de processamento, alto teor calórico, grande quantidade de gordura, açúcar e sal, e muito pouco ou mesmo nenhum micronutriente importante (Tojo, Leis, Recarey, \& Pavon, 1995). Nos EUA, Kotz e Story (1994) verificaram que, de uma amostra de anúncios de alimentos na televisão, 43,6 \% eram classificados no grupo de gordura, óleos e doces, seguidos de 37,5\% no grupo de pão, cereal, arroz e massa, dos quais $23 \%$ eram de cereais com alta taxa de açúcar. Os anúncios de alimentos para o café da manhã consistiam em combinações de torradas, salsicha e batatas fritas; ovos mexidos, rosca doce e salsicha; waffers, salsicha e batatas fritas. As combinações para as refeições de almoço e jantar consistiam de empanados de frango, hamburger ou pizza e, para sobremesa, milho.

No Brasil a situação não é muito diferente. Almeida et al. (2002) analisaram as propagandas das três maiores redes de canal aberto da televisão mostrando que o item mais freqüientemente veiculado foi alimentos, independente da rede de televisão, do horário de veiculação e do dia da semana. Os dados obtidos revelaram que, dos 1395 anúncios de produtos alimentícios, $57,8 \%$ foram classificados no grupo das gorduras, óleos, açúcares e doces. O segundo maior grupo foi representado pelos pães, cereais e massas $(21,2 \%)$, seguido pelo grupo dos leites, queijos e iogurtes $(11,7 \%)$ e pelo grupo das carnes, ovos e leguminosas $(9,3 \%)$. Observou-se uma completa ausência de pro- 
dutos no grupo das verduras e frutas. Além disso, as informações nutricionais dos alimentos fornecidas pelos comerciais de não são completas e adequadas. Elas omitem dados e não revelam as consequiências da ingestão excessiva ou da falta de determinados nutrientes. Um estudo de Amancio e Grazin (2000) com adolescentes concluiu que a maioria dos comerciais foi de salgadinhos empacotados e refrigerantes e que $82,4 \%$ dos alimentos identificados se relacionaram aos hábitos alimentares.

Esses dados são extremamente preocupantes, pois sabemos que os anúncios de alimentos na televisão influenciam os padrões de compra da família e que um dos mecanismos mais importantes para isso são os pedidos das próprias crianças para que os pais comprem os alimentos vistos na televisão (Taras, Sallis, Patterson, Nader \& Nelson, 1989). Aliado a esta influência dos comerciais, outro dado preocupante é o número de horas que crianças e adolescentes despendem diante da televisão. Estima-se que crianças norteamericanas vejam 20.000 anúncios por ano, onde mais da metade são anúncios de alimentos (Strasburger, 1992). Essas mesmas crianças passam mais tempo assistindo televisão do que fazendo outra atividade que não seja dormir (Dietz, 1990). Baseados nesses dados e em outros do próprio grupo Taras e Gage (1995) concluíram as crianças assistem uma média de 21,3 comerciais por hora, com duração média de 28,6 segundos cada, sendo $91 \%$ dos alimentos anunciados ricos em gordura, açúcar e/ou sal. Um trabalho de Klesges, Shelton e Klesges (1993) indica que a taxa metabólica é significantemente reduzida enquanto se assiste televisão. O maior tempo despendido diante da televisão parece contribuir duplamente para o aumento da obesidade. Por um lado predispõe o telespectador a consumir os alimentos veiculados e, por outro, aumenta o tempo de inatividade. Neste sentido, Gupta, Saini, Acharya e Miglani (1994), estudando os efeitos do comportamento de assistir televisão sobre os hábitos alimentares e atividades físicas das crianças verificaram redução na atividade física, aumento no peso corporal e um maior consumo de alimentos com sabor adocicado. Estes dados foram confirmados por outros mostrando que, além das mudanças no hábito alimentar, as crianças e adolescentes diminuíram drasticamente a atividade física e, conseqüentemente, o gasto energético como resultado de um maior tempo assistindo programas de televisão, usando o computador ou brincando no vídeo game (Gortmaker et al. 1996; Lerner, 2000). Estes dados são relevantes quando se constata que 
Determinantes Psicobiológicos do Comportamento Alimentar: uma Ênfase...

a cada hora de inatividade frente a televisão aumenta em até $2 \%$ a prevalência de obesidade (Dietz, 1990).

As causas associadas à obesidade são várias: hábito de comer demais e erroneamente, influência genética, meio ambiente e nível de atividade física. As causas genéticas não podem ser modificadas, mas as causas ambientais podem ser alteradas com orientação. Os desequilíbrios nutricionais estão cada vez mais preocupantes e a obesidade infantil aumentando $50 \%$ na última década com cerca de $1 / 4$ das crianças com sobrepeso ou obesidade. Estima-se que $50 \%$ das crianças obesas aos sete anos serão adultos obesos, ao passo que $80 \%$ dos adolescentes obesos se tornarão adultos obesos (Monteiro, Victora, Barros, \& Tomasi, 2000; Must, 1996). Além disso, a aterosclerose e a hipertensão arterial, doenças típicas do adulto, são situações clinicas que, em muitos casos, começaram na infância e adolescência (Oliveira, 2000). A obesidade é uma das doenças nutricionais que mais tem aumentado, não apenas nos países ricos, mas também em países em desenvolvimento como o Brasil, aumentando sua prevalência especialmente nas regiões mais ricas, como o Sul e Sudeste (Escrivão, Oliveira, Tadei, \& Lopez, 2000). Fisberg e Rodrigues (2000) verificaram que $85 \%$ das crianças iniciaram a obesidade na fase de lactente e pré-escolar, sendo que em $90 \%$ dos casos apresentavam sedentarismo e em 9,3\% dos casos pelo menos um dos exames de lipídeo alterado. Dados estes confirmados por Moura, Castro, Mellin e Figueiredo (2000) mostrando uma prevalência de hipercolesterolemia de $35 \%$ em crianças de 7 a 14 anos.

\section{Adolescentes: as preferências se consolidam}

As crianças crescem e, cada vez mais, tornam-se independentes até chegar à adolescência, onde se sentem capazes de tomar suas próprias decisões a respeito dos mais variados assuntos, inclusive o seu padrão alimentar. A adolescência é o período de transição caracterizada por intenso crescimento e desenvolvimento, ocorrendo transformações fisiológicas, anatômicas, psíquicas, emocionais e sociais (Maham \& Escott-Stump, 1998). No início da adolescência o jovem já atingiu 80 a $85 \%$ de sua estatura, 53\% de seu peso e $52 \%$ da massa esquelética final (Escott-Stump, 1999). 
Nesta fase o jovem necessita de maior quantidade de macro e micronutrientes e, ao mesmo tempo, tem que se inserir a um grupo social, passando a assumir os mesmos hábitos costumes e valores, consumindo lanches, refrigerantes, salgadinhos em excesso, levando a um desequilíbrio na dieta e, portanto, a um sobrepeso ou obesidade. Estudos relacionados à preferência alimentar dos adolescentes mostraram alta preferência por massas, doces, gorduras e refrigerantes e um consumo inadequado de frutas e vegetais (Carvalho, Nogueira, Teles, Paz, \& Sousa, 2001; Fernandes, Ferraz, Pereira, Polônio, \& Serra, 2000; NeumarkSztainer, Story, Resnick, \& Blum, 1996). Assim, o elevado consumo de alimentos ricos em gordura e com elevado teor calórico, associado a um baixo consumo de vegetais, grãos e frutas pode acarretar, no futuro, doenças, como cardiopatias, hipertensão arterial, diabetes, osteoartrite e câncer, entre outras (Cavadini, 1995). Entre os adolescentes também é comum encontramos problemas como a omissão de refeições, principalmente o café da manhã, ou mesmo a substituição de refeições principais por lanche. Crianças que suprimem o café da manhã tendem a serem mais gordas que aquelas que fazem o desjejum (Wolfe, Campbell, Frongillo Jr., Haas, \& Melnik, 1984). No Brasil os traços marcantes e negativos da evolução do padrão alimentar através de orçamentos familiares mostram uma tendência crescente na proporção de calorias lipídicas na dieta do Norte e Nordeste; a manutenção desse indicador em torno de valores muito elevados no Centro-Sul e a persistência de valores elevados para o colesterol dietético. Há também aumento dos ácidos graxos saturados e redução dos carboidratos complexos em todas as áreas metropolitanas do país, ao lado da estagnação ou redução do consumo de leguminosas, verduras, legumes, frutas e sucos naturais, e da ascensão do consumo já excessivo de açúcar refinado e refrigerantes (Monteiro, Mondini, \& Costa, 2000).

Além dos problemas discutidos acima o adolescente obeso enfrenta problemas relacionados ao aspecto emocional. Sente-se discriminado pelos colegas e pode desenvolver complicações físicas como dificuldade de movimentação, problemas ortopédicos e de postura. O grande problema é que estes efeitos somente aparecem a longo prazo na saúde destes adolescentes, que muitas vezes estão mais preocupados com os efeitos imediatos dos alimentos que consomem (Bull, 1992). Os adolescentes também estão sujeitos às influências da propaganda, de modismo, dos amigos, da família, e do grupo social e cultural no qual está inserido. Neste ponto merece destaque a análise das mensagens conflitantes a que estão expostos. Se por um lado os meios de comunicação e as campanhas 
Determinantes Psicobiológicos do Comportamento Alimentar: uma Ênfase...

de saúde pública veiculam mensagens de consumo de uma dieta equilibrada, saudável e variada além da prática de atividades físicas, por outro as industrias alimentícias veiculam inúmeras mensagens promovendo o consumo de todo o tipo de itens alimentares. Também aqui, como discutido na seção anterior, é grande o poder da mídia no estabelecimento dos hábitos alimentares. Todos estes fatores podem facilitar a modificação dos seus hábitos alimentares fazendo com que troquem a alimentação habitual pelo consumo de lanches rápidos (Bull, 1992; Gambardella, Frutuoso, \& Franchi, 1999). Além disso, outros fatores importantes dizem respeito ao tipo de vida atual com insegurança nas ruas e maior tempo dentro de casa em atividades sedentárias como assistir à televisão, brincar com o vídeo game e utilizar o computador, atividades estas que substituíram brincadeiras como pedalar bicicleta, jogar bola, pular corda, entre outras. O sedentarismo cada vez mais frequiente, aliado às mudanças drásticas nos hábitos alimentares, fez da obesidade em adolescentes uma verdadeira epidemia.

\section{Adultos: hábitos formados, surgem as primeiras conseqüiências.}

A família mudou drasticamente nas ultimas décadas em todos os sentidos. O grupo familiar foi reduzido, a mulher passou a ter uma maior participação na renda familiar trabalhando fora de casa, e os filhos passaram a ser cuidados em berçários, creches e escolas de tempo integral, quando não por empregadas domésticas. Com todas estas mudanças não seria de se esperar que o padrão alimentar permanecesse inalterado.

A mulher, tradicionalmente tida como o membro do casal que deveria cuidar da educação e alimentação dos filhos, não está em casa o tempo todo e tem que conciliar a carreira profissional com as tarefas domésticas. Este novo perfil de grupo familiar foi logo percebido e explorado pelas indústrias alimentícias. A comodidade e a praticidade na aquisição e preparo de refeições rápidas foram os principais argumentos utilizados pelas indústrias para seduzir os responsáveis pela aquisição dos alimentos e mudar hábitos de consumo.

Este novo padrão de consumo e ingestão de alimentos tem produzido dados interessantes. Monteiro, Mondini, De Souza e Popkin (1995) mostra que no Brasil a desnutrição tem decrescido entre adultos e crianças, embora 
ainda seja um problema em crianças de famílias de baixa renda em algumas regiões do país. Por outro lado, ocorreu um aumento da obesidade entre todos os grupos de homens e mulheres, com a maior proporção de aumento entre famílias de baixa renda. $\mathrm{O}$ autor conclui que o Brasil está rapidamente mudando de um problema de deficiência nutricional para um problema de excesso alimentar. Contribuindo para esta mudança certamente está a grande alteração no padrão de alimentação das famílias brasileiras.

Com todas estas alterações nos hábitos alimentares aumentou drasticamente o número de adultos jovens obesos tanto em países desenvolvidos como em países em desenvolvimento como o Brasil (Popkin, 1998; Vand Der Ploeg, 2000). Como consequiência é cada vez mais freqüiente o aparecimento precoce de doenças crônicas como hipertensão, diabetes, osteoartrite, arterosclerose, derrames, câncer e outros decorrentes de maus hábitos alimentares associados ao sedentarismo (Nawaz \& Katz, 2001).

Embora a questão genética tenha ganhado bastante evidência recentemente, não se acredita que a grande epidemia de obesidade possa ser atribuída apenas aos genes (Carlos Poston II \& Foreyt, 1999), uma vez que o genoma humano não se modificou em milhares de anos. Estes mesmos autores acreditam que o ambiente tem prevalência como explicação para a epidemia de obesidade em todo o mundo. Entre as características do ambiente que promoveriam a obesidade os autores citam: aumento da produção e ingestão de alimentos, aumento do tamanho das porções consumidas, redução de atividade física, e baixo status socioeconômico.

\section{Considerações finais}

A multiplicidade de fatores ambientais que contribuem para a obesidade requer ações também múltiplas se pretendemos elaborar programas para a redução dos índices de obesidade na população. Algumas soluções ambientais e políticas têm sido propostas na literatura (Carlos Poston II \& Foreyt, 1999) e incluem o que se chama de medidas progressivas e medidas regressivas. Entre as progressivas encontramos: 1) promover pesquisas tecnológicas para a produção de alimentos nutritivos e de baixa densidade calórica; 2) prover subsídios para alimentos saudáveis como frutas e vegetais; 3 ) criar comunidades 
Determinantes Psicobiológicos do Comportamento Alimentar: uma Ênfase...

com centros de atividade e pistas para bicicletas e pedestres; 4) promover atividade física regular nas escolas; 5) prover reembolsos de seguro para indivíduos que sejam aprovados em testes físicos e 6) permitir que os trabalhadores utilizem suas licenças em haver para férias. Entre as regressivas encontramos: 1) taxar alimentos densamente calóricos; 2) regular propagandas de alimentos, especialmente auqelas direcionadas às crianças e jovens e 3) limitar o acesso a alimentos densamente calóricos em escolas. Além disso, deve-se também levar em consideração a educação nutricional de crianças e adolescentes, orientação junto aos pais, trabalho nas escolas como ação preventiva na formação de hábitos alimentares e de atividades físicas adequados, intervenção nas escolas através de treinamento de professores, além de uma política governamental de alimentação e nutrição.

Por outro lado, o fato do número obesos estar aumentando consistentemente na maioria dos países, apesar dos esforços de educação nutricional e campanhas de incentivo a atividades físicas, mostra que o problema provavelmente não é apenas a falta de educação nutricional ou mesmo uma inadequada força do desejo dos obesos em perder peso. Dados recentes (Quaioti, 2002) ilustram bem esta questão. Neste estudo era dada às crianças e adolescentes a oportunidade de escolherem três itens alimentares para comporem um lanche a ser consumido no intervalo das aulas. $\mathrm{O}$ item mais freqüentemente foi um "salgadinho" frito em óleo; seguido de outro salgadinho tipo "chips" e de um refrigerante. Quando a estas mesmas crianças foi perguntado o que elas consideravam um lanche saudável as escolhas foram uma fruta, um suco de fruta e leite. À pergunta do que os pais gostariam que ela escolhesse como lanche as escolhas foram uma fruta, um pão e leite. Finalmente, à pergunta do que os pais escolheriam para lanche, embora a maioria das crianças tenha citado frutas, pão e leite, também apareceu em terceira opção os "salgadinhos" fritos. Estes dados mostram, de forma clara, que o problema não parece ser cognitivo, mas motivacional/emocional, ou seja, as crianças têm o conhecimento do que seria um lanche saudável, sabem o que os seus pais gostariam que elas consumissem, mas quando às mesmas é dada a oportunidade de escolha preferem os lanches ricos em doces, gorduras e sal. Estes dados mostram que o desafio que a sociedade tem que enfrentar para reduzir os índices de obesidade da população não passa somente pelo aumento de informações para o indivíduo, mas por alterações marcantes no ambiente social. Isto significa uma mudança no 
lócus de responsabilidade do indivíduo para o ambiente, como têm defendido alguns autores (Schwartz \& Puhl, 2003).

Quaioti, T. C. B., \& Almeida, S. S. (2006). Psychobiological determinants of food behavior: An emphasis on environmental factors contributing to obesity. Psicologia USP, 17(4), 193-211.

\begin{abstract}
Thefoodbehaviorismultideterminedandonlyapsychobiological analysis can comprise the relations among physiological, genetic and psychological factors, as wall as, the environmental conditions. Thus, the capability to control the food ingestion request specialized mechanisms to harmonize physiological information of internal environment with nutritional information of external environment. Regarding the external factors deserves importance the question related to food advertising and the midia influence in the determination of the people diet in developed and developing nations. Thus, the aim of the present work is to review the environmental factors that determine the human food behavior, with special emphasis on that factors that can predispose to obesity.
\end{abstract}

Index terms: Feeding practices. Environment. Obesity.

Quaioti, T. C. B., \& Almeida, S. S. (2006). Déterminants psychobiologiques du comportement alimentaire: l'emphase des facteurs environnementaux qui contribuent à l'obésité. Psicologia USP, 17(4), 193-211.

Résumé: Le comportement alimentaire est multideterminé et seulement une analyse psycho-biologique est capable de saisir les interactions entre les facteurs physiologiques, psychologiques, génétiques et les conditions environnementales d'um individu. Ainsi, la capacité pour contrôler l'ingestion d'aliments exige des mécanismes spécialisés pour harmoniser des informations physiologiques du milieu interne avec des informations nutritionnelles de l'environnement externe. Parmi les facteurs externes, la propagande d'aliments et l'influence chaque fois plus grande de la mídia dans la détermination de la diète des personnes de pays développés ou 
Determinantes Psicobiológicos do Comportamento Alimentar: uma Ênfase...

dans en développement méritent être ressorties. Ainsi, le présent travail a pour objectif analyser les influences des facteurs environnementaux dans la détermination du comportement alimentaire humain, avec une emphase espéciale des facteurs qui peuvent predisposer à l'obésité.

Mots-clés : Comportement alimentaire. Environnement. Obésité.

\section{Referências}

Almeida, S. S., Nascimento, P. C. B. D., \& Quaioti, T. C. B. (2002). Quantidade e qualidade dos produtos alimentícios anunciados na televisão brasileira. Revista de Saúde Pública, 36(3), 353-355.

Amâncio, O. M. S., \& Grazin, J. T. (2000). Comerciais de alimentos e hábitos alimentares de adolescentes. In Anais do Conselho Regional de Nutricionistas, $3^{a}$ Região. São Paulo: CRN-3.

Asp, E. H. (1999). Factors affecting food decisions made by individual consumers. Food Policy, 24(1-2), 287-294.

Birch, L. L. (1992). Children's preferences for high-fast foods. Nutrition Reviews, 50(9), 249-255.

Birch, L. L. (1998). Development of food acceptance in the first years of life. The Proceedings of the Nutritional Society, 57(4), 617-24.

Birch, L. L. (1999). Os padrões de aceitação do alimento pelas crianças. In Anais Nestlé, 57 (pp. 12-20). São Paulo: Nestlé.

Birch, L. L., \& Fisher, J. A. (1995). Appetite and eating behavior in children. Pediatric Clinics of North America, 42(4), 931-953.

Birch, L. L., \& Fisher, J. A. (1997). The role of experience in the development of children's eating behavior. In E. D. Capaldi (Ed.), Why we eat what we eat: The psychology of eating (2nd ed., pp. 113-141). Washington, DC: APA.

Birch, L. L., \& Fisher, J. O. (1998). Development of eating behaviors among children and adolescents. Pediatrics, 101(Suppl. 3), 539-549.

Bull, N. L. (1992). Dietary habits, food consumptions, and nutrient intake during adolescence. The Journal of Adolescent Health, 13(5), 384-388.

Caldeira, G. V. (2000). Fatores que influenciam a formação dos hábitos alimentares de crianças. In Anais do Simpósio Sul Brasileiro de Alimentação e Nutrição: História, Ciência e Arte (pp. 181-185). Florianópolis: Universidade Federal de Sana Catarina. 
Carlos Poston II, W. S., \& Foreyt, J. P. (1999). Obesity is an environmental issue. Atherosclerosis, 146(2), 201-219.

Carvalho, C. M. R. G., Nogueira, A. M. T., Teles, J. B. M., Paz, S. M. R., \& Sousa, R. M. L. (2001). Consumo alimentar de adolescentes matriculados em colégio particular de Teresina, Piauí, Brasil. Revista de Nutrição, 14(2), 85-93.

Catania, A. C. (1999). Aprendizagem: comportamento, linguagem e cognição. Porto Alegre: Artes Médicas Sul.

Cavadini, C. (1995). Hábitos dietéticos durante a adolescência: contribuição dos lanches. In Nestlé Nutrition Services (Seminário Nestlé Nutrition, 37). A alimentação da idade préescolar até a adolescência (pp. 11-13). São Paulo: Nestlé.

Cowart, B. (1981). Development of taste perception in humans: Sensitivity and preference throughout the life span. Psychological Bulletin, 90(1), 43-73.

De Assis, M. A. A. (2000). Comportamento alimentar e ritmos circadianos de consumo. In Anais do Simpósio Sul Brasileiro de Alimentação e Nutrição: História, Ciência e Arte (pp. 17-21). Florianópolis: Universidade Federal de Santa Catarina.

De Castro, J. M., \& Plunkett, S. S. (2001). How genes control real world intake: Palatability intake relationships. Nutrition, 17(3), 266-268.

Dietz, W. H. (1990). You are what you eat: What you eat is what you are. Journal of Adolescent Health Care, 11(1), 76-81.

Escott-Stump, S. (1999). Nutrição relacionada ao diagnóstico e tratamento (4a ed.). São Paulo: Manole.

Escrivão, M. A. M. S., Oliveira, F. L. M., Tadei, J. A. A. C., \& Lopez, F. A. (2000). Obesidade exógena na infância e na adolescência. Jornal de Pediatria, 76(Supl. 3), 305-310.

Fernandes, C. S., Ferraz, L. M., Pereira, T. J., Polônio, M. L. T., \& Serra, G. M. A. (2000). Adolescentes: consumidor potencial de produtos dietéticos. Cadernos NEPEN, 9, 65-69.

Fisberg, M., \& Rodrigues, L. (2000). Fatores de risco na obesidade da adolescência. In Simpósio Obesidade e Anemia Carencial na Adolescência (pp. 219-220). São Paulo: Instituto Danone.

Fonseca, V. M., Sichieri, R., \& Veiga, G. V. (1998). Fatores associados à obesidade em adolescentes. Revista de Saúde Pública, 32(6), 541-549.

Galef, B. G. (1982). Studies in social learning in Norway rats: A brief review. Developmental Psychobiology, 15(4), 279-295.

Galef, B. G., \& Handerson, P. W. (1972). Mother's milk: As determinant of the feeding preferences of weaning rat pups. Journal of Comparative and Physiological Psychology, 78(2), 213-219. 
Determinantes Psicobiológicos do Comportamento Alimentar: uma Ênfase...

Gallo, A. E. (1998). Food advertising in the United States. America's eating habits: Changes and consequences. Food and Rural Economics Division, Economic Research Service, US Department of Agriculture. Recuperado em 21 de julho de 2006, da Base de Dados http://www.ers.usda.gov/publications/AIB750/AIB750.pdf

Gambardella, A. M. D., Frutuoso, M. F. P., \& Franchi, C. (1999). Prática alimentar de adolescentes. Revista de Nutrição, 12(1), 55-63.

Gortmaker, S. L., Must, A., Sobol, A. M., Peterson, K., Golditz, G. A., \& Dietz, W. H. (1996). Television viewing as a cause of increasing obesity among children in the United States, 1986-1990. Archives of Pediatrics \& Adolescent Medicine, 150(4), 356-362.

Gupta, R. K., Saini, D. P., Acharya, U., \& Miglani, N. (1994). Impact of television on children. Indian Journal of Pediatrics, 61(2), 153-159.

Klesges, R. C., Shelton, M. L., \& Klesges, L. M. (1993). Effects of television on metabolic rate: Potential implications for childhood obesity. Pediatrics, 91(2), 281-286.

Koivisto, U. K., \& Sjödén, P. O. (1996). Reasons for rejection of food items in Swedish families with children aged 2-17. Appetite, 26(1), 89-103.

Kotz, K., \& Story, M. (1994). Food advertisements during children's Saturday morning television programming: Are they consistent whit dietary recommendations? Journal of the American Dietetic Association, 94(11), 1296-1300.

Krebs-Smith, S. M., Cook, D. A., Subar, A. F., Cleveland, L., Friday, J., \& Kahle, L. L. (1996). Fruit and vegetable intakes of children and adolescents in the United States. Archives of Pediatrics \& Adolescent Medicine, 150(1), 81-86.

Lerner, R. L. (2000). Perfil de consumo. In Simpósio: Obesidade e Anemia Carencial na Adolescência (pp. 147-159). São Paulo: Instituto Danone.

Maham, L. K., \& Escott-Stump, K. (1998). Alimentos, nutrição e dietoterapia (9a ed.). São Paulo: Roca.

Mariani-Costantini, A. (2000). Natural and cultural influences on the evolution of the human diet: Background of the multifactorial processes that shaped the eating habits of the western societies. Nutrition, 16(7-8), 483-486.

Martins-Filho, J. M. (2001). Masculino X feminino: os diferentes hábitos alimentares de crianças e jovens. Nutrição Saúde \& Performance, 3(10), 31.

Milton, K. (2000). Back to basics: Why foods of wild primates have relevance for modern human health. Nutrition, 16(7-8), 480-483.

Monteiro, C. A., Mondini, L., \& Costa, R. B. (2000). Mudanças na composição e adequação nutricional da dieta familiar nas áreas metropolitanas do Brasil (1988-1996). Revista de Saúde Pública, 34(3), 251-258. 
Monteiro, C. A., Mondini, L., De Souza, A. L., \& Popkin. B. M. (1995). The nutrition transition in Brazil. European Journal of Clinical Nutrition, 49(2), 105-113.

Monteiro, P. O. A., Victora, C. G., Barros, F. C., \& Tomasi, E. (2000). Diagnóstico de sobrepeso em adolescentes: estudo do desempenho de diferentes critérios para o Índice de Massa Corporal. Revista de Saúde Pública, 34(5), 506-513.

Moura, E. C., Castro, C. M., Mellin, A. S., \& Figueiredo, D. B. (2000). Perfil lipídico em escolares de Campinas, SP, Brasil. Revista de Saúde Pública, 34(5), 499-505.

Must, A. (1996). Morbidity and mortality associated whit elevated body weight in children and adolescents. American Journal of Clinical Nutrition, 63(Suppl. 3), 445S-447S.

Nawaz, H., \& Katz, D. L. (2001). American College of Preventive Medicine Practice Policy Statement: Weight management counseling of overweight adults. American Journal of Preventive Medicine, 21(1), 73-78.

Netto, C. A. (1998). Psicobiologia do comportamento alimentar. In M. A. A Nunes, J. C. Appolinário, A. L. G. Abuchaim \& V. Coutinho (Eds.), Transtornos alimentares e obesidade (pp. 47-53). Porto Alegre: Artmed.

Neumark-Sztainer, D. D., Story, M., Resnick, M. D., \& Blum, R. W. (1996). Correlates of inadequate fruit and vegetable consumption among adolescents. Preventive Medicine, 25(5), 497-505.

Oliveira, R. G. A. (2000). Obesidade na infância e adolescência como fator de risco para doenças cardiovasculares do adulto. In Simpósio Obesidade e Anemia Carencial na Adolescência (pp. 65-75). São Paulo: Instituto Danone.

Popkin, B. M. (1998). Worldwide trends in obesity. Nutritional Biochemistry, 9(9), 487-488.

Quaioti, T. C. B. (2002). Hábitos e preferências alimentares de crianças e adolescentes do ensino fundamental de escolas particulares: uma análise de fatores ambientais no estudo da obesidade. Tese de Doutorado, Faculdade de Filosofia, Ciências e Letras de Ribeirão Preto, Universidade de São Paulo, Ribeirão Preto, São Paulo.

Ramos, M., \& Stein, L. M. (2000). Desenvolvimento do comportamento alimentar infantil. Jornal de Pediatria, 76(Supl. 3), 228-237.

Schwartz, M. B., \& Puhl, R. (2003). Childhood obesity: A societal problem to solve. Obesity Reviews, 4(1), 57-71.

Strasburger, V. C. (1992). Children, adolescents and television. Pediatrics in Review, 13(4), $144-51$.

Sullivan, S. A., \& Birch, L. L. (1994). Infant dietary experience and acceptance of solid foods. Pediatrics, 93(2), 271-277. 
Determinantes Psicobiológicos do Comportamento Alimentar: uma Ênfase...

Taras, H. L., \& Gage, M. (1995). Advertised foods on children's television. Archives of Pediatrics \& Adolescent Medicine, 149(6), 649-6452.

Taras, H. L., Sallis, J. F., Patterson, T. L., Nader, P. R., \& Nelson J. A. (1989). Television's influence on children's diet and physical activity. Journal of Developmental and Behavioral Pediatrics, 10(4), 176-180.

Tojo, R., Leis, R., Recarey, M. D., \& Pavon, P. (1995). Hábitos alimentares das crianças em idade pré-escolar: riscos para a saúde e estratégias para a intervenção. In Nestlé Nutrition Services (Seminário Nestlé Nutrition, 37). A alimentação da idade pré-escolar até a adolescência (pp. 11-13). São Paulo: Nestlé.

Vand Der Ploeg, L. H. (2000). Obesity: An epidemic in need of therapeutics. Current Opinion in Chemical Biology, 4(4), 452-460.

Wolfe, W. S., Campbell, C. C., Frongillo Jr., E. A., Haas, J. D., \& Melnik, T. A. (1994). Overweight schoolchildren in New York State: Prevalence and characteristics. American Journal of Public Health, 84(5), 807-813.

Recebido em: 9/09/2006

Aceito em: 13/11/2006 